\title{
Calcium supplementation and bone mineral accretion in Chinese adolescents aged 12-14 years: a 12-month, dose-response, randomised intervention trial
}

\author{
Xiao-ming $\mathrm{Ma}^{1}$, Zhen-wu Huang ${ }^{2}$, Xiao-guang Yang ${ }^{2 *}$ and Yi-xiang $\mathrm{Su}^{1 *}$ \\ ${ }^{1}$ Guangdong Provincial Key Laboratory of Food, Nutrition and Health, Department of Nutrition, \\ School of Public Health, Sun Yat-sen University, Guangzhou 510080, People's Republic of China \\ ${ }^{2}$ Key Lab of Trace Element Nutrition of Ministry of Health, National Institute for Nutrition and Food Safety, \\ Chinese Center for Disease Control and Prevention, Beijing 100021, People's Republic of China \\ (Submitted 8 July 2013 - Final revision received 9 July 2014 - Accepted 11 July 2014 - First published online 18 September 2014)
}

\begin{abstract}
A 12-month, dose-response, randomised, intervention trial was conducted to determine adequate Ca intake levels for Chinese adolescents by investigating the effect of Ca supplementation on bone mineral accretion. A total of 220 Han adolescents (111 girls and 109 boys) aged 12-14 years were recruited. All subjects were randomly divided into three groups. The bone mineral content (BMC) and bone mineral density (BMD) of the whole body, lumbar spine (L1-L4), left hip and femoral neck were measured by dual-energy X-ray absorptiometry. Girls in the high-Ca group (actual Ca intake: 1243 (sD 193) mg/d) exhibited greater increases in the femoral neck BMC compared with those in the low-Ca group ( $9.7 v \cdot 6.4 \%, P=0.04)$ over the 1-year intervention period. The increases in femoral neck BMC were greater in boys in the high-Ca and medium-Ca groups (actual Ca intake: 985 (SD 168) mg/d) than in those in the low-Ca group $(15 \cdot 7 v .11 \cdot 7 \%, P=0 \cdot 03 ; 15 \cdot 8$ $v .11 .7 \%, P=0.03)$. Ca supplementation had significant effects on the whole-body BMC and BMD in subjects with physical activity levels $>34.86$ metabolic equivalents and on the spine BMD and BMC and BMD of most sites in subjects with Tanner stage $<3$. Increasing $\mathrm{Ca}$ intake levels with Ca supplementation enhanced femoral neck mineral acquisition in Chinese adolescents. Furthermore, high physical activity levels and low Tanner stage appeared to significantly contribute to the effect of Ca supplementation on bone mass. Whether this is a lasting beneficial effect leading to the optimisation of peak bone mass needs to be determined in other long-term prospective studies.
\end{abstract}

Key words: Calcium supplementation: Early adolescence: Bone mineral content: Bone mineral density: Tanner stages

\section{Background}

Ca deposition in bones is an ongoing process that occurs throughout childhood and persists into adolescence, reaching maximal levels during the pubertal growth spurt ${ }^{(1)}$. Bone mineral density (BMD) acquisition during childhood and adolescence is very important for adult bone mass accrual and skeletal formation ${ }^{(2,3)}$, as approximately $45-50 \%$ of the adult skeletal mass is acquired during these periods. Therefore, childhood and adolescence are considered to be crucial periods for maximising genetically predetermined peak bone mass through the modification of lifestyle and environmental factors. Peak bone mass and subsequent bone losses are important determinants of osteoporosis later in life ${ }^{(4)}$. Maximising peak bone mass is advocated as a way to prevent osteoporosis. As a prerequisite to the elaboration of any preventive programme aimed at maximising peak bone mass, it is important to determine how the rate of skeletal growth at clinically relevant sites, such as lumbar spine and femoral neck, proceeds in relation to age and pubertal stages in both sexes ${ }^{(5)}$.

Even though genetic predisposition determines up to $80 \%$ of peak bone mass ${ }^{(6)}$, environmental factors such as nutrition and physical activity play important roles in the achievement of maximum bone mass ${ }^{(7)}$. Given the uncertainties in understanding the cumulative impact of genetic and environmental factors on bone mass throughout life, the question of whether maximal, optimal or 'peak' bone mass can be achieved on a lasting basis through dietary manipulation and/or use of supplements has not been resolved completely ${ }^{(1)}$. Although $\mathrm{Ca}$ increases the parallel markers of bone formation, which supports the hypothesis that $\mathrm{Ca}$ intake during the early-to-late

Abbreviations: BMC, bone mineral content; BMD, bone mineral density; DRI, dietary reference intake; DXA, dual-energy X-ray absorptiometry; MET, metabolic equivalents.

*Corresponding authors: X.-g. Yang, fax + 8610 83132798, email xgyangcdc@vip.sina.com; Y.-x. Su, fax + 862087333166 , email suyx@mail.sysu.edu.cn 
pubertal stage influences the peak rates of $\mathrm{Ca}$ deposition in bones during pubertal development, the role of $\mathrm{Ca}$ intake in bone mineralisation during adolescence remains controversial $^{(8-12)}$. An earlier study has followed prepubertal males and females for 18 months after $\mathrm{Ca}$ supplementation and found gains in the bone mineral content (BMC) and bone area of the lumbar spine; however, the increases in bone accretion disappeared after the withdrawal of supplementation ${ }^{(13)}$. In a longer-term randomised clinical trial, Matkovic et al. ${ }^{(14)}$ evaluated the effects of Ca supplementation on bone accretion during the transition from childhood to early adulthood. They found significant increases in bone accretion for total bone density and distal and proximal radius and metacarpal indices after 4 years of supplementation; by 7 years, however, only the proximal radius and metacarpal indices still exhibited significantly increased bone accretion in non-supplemented controls. These findings corroborate a role for $\mathrm{Ca}$ intake in skeletal formation; however, they also suggest that bone accretion diminishes during skeletal consolidation in late adolescence, and attainment of peak bone mass was transient for some skeletal sites, even though the study subjects continued using Ca supplements through year 7 .

There is also much evidence indicating that improvements in bone mass can occur through physical activity and $\mathrm{Ca}$ intake. However, such studies are limited in Asian children and adolescents. The Chinese dietary reference intake (DRI) ${ }^{(15)}$ suggests that adequate Ca intake levels for children and adolescents are 800 and $1000 \mathrm{mg} / \mathrm{d}$, respectively, which are based on data from Western countries. In reality, $\mathrm{Ca}$ intake levels of mainland Chinese adolescents are consistently reported at approximately $300-440 \mathrm{mg} / \mathrm{d}^{(16)}$, which are much lower than the DRI. Whether these levels meet the needs of Chinese adolescents requires evaluation in these individuals.

Because of inconclusive data on Asian adolescents, the synergistic relationship between $\mathrm{Ca}$ intake and other factors such as physical activity, and the fact that most previous studies on the effect of $\mathrm{Ca}$ supplementation on bone mass accretion were based on two groups (control and supplement), the optimal $\mathrm{Ca}$ intake levels for achieving maximum bone mass have not been determined. The present study investigated the dynamic development of BMC and BMD with three doses of $\mathrm{Ca}$ supplementation in 12- to 14-year-old adolescents for 1 year using dual-energy X-ray absorptiometry (DXA) to determine Ca intake levels necessary for maximising bone mass based on sex, pubertal stage, ethnicity and physical activity levels.

\section{Subjects and methods}

\section{Subjects}

The present study was a double-blind, randomised, 1-year longitudinal intervention trial. In total, 374 of the 1346 firstgrade students from four middle schools in urban Guangzhou, in southern China, were recruited between November 2009 and February 2010. Of these 374 students, 220 Han adolescents (including 111 girls and 109 boys) aged 12-14 years with good compliance (evaluated by retrieving milk drinking diaries and food records) were included in the formal study and randomly assigned to one of the three study groups. Subjects with the following conditions or behaviours were excluded: fracture or recovery from fracture in the previous year; consumption of vegetarian diet; consumption of Ca supplements or any other medications that affect bone metabolism; history of deformity, hereditary disease, psychosis, cancer, thyroid disease, parathyroid disease, renal failure or autoimmune diseases. The present study was conducted according to the guidelines set forth by the Declaration of Helsinki, and all procedures involving human subjects were approved by the Research Ethics Committee of Sun Yat-sen University. Written informed consent was obtained from all subjects.

A randomisation schedule for all subjects was stratified by the median BMD of the lumbar spine (L1-L4). Block randomisation in block intervals of 15 was used for the random assignment of subjects. A list of random numbers was generated using a computer. Researchers with no contact with the study subjects and who were not involved in data collection or analysis performed the randomisation and labelled the supplements. Serial numbers and the corresponding supplements were assigned to the eligible subjects in the order of final enrolment in the trial. The subjects, investigators and laboratory technicians were blinded to the treatment assignment until the conclusion of the trial.

The subjects were assigned to one of the following three intervention groups: low $\mathrm{Ca}$ ( $40 \mathrm{~g}$ milk powder $+5 \mu \mathrm{g}$ (200 IU) vitamin D); medium Ca (40 g milk powder $+300 \mathrm{mg}$ $\mathrm{Ca}+5 \mu \mathrm{g}$ (200 IU) vitamin $\mathrm{D}) ;$ high Ca (40g milk powder $+600 \mathrm{mg} \mathrm{Ca}+5 \mu \mathrm{g}$ (200 IU) vitamin D). Thus, the total supplemental Ca levels were 300, 600 and $900 \mathrm{mg} / \mathrm{d}$ for the low-Ca, medium-Ca and high-Ca groups, respectively.

All milk powders used in the present study had the same colour, appearance and smell. Each package was labelled 'special calcium supplement', with group A, B or C denoted on the box. The supervisor of the project generated the group and the number code for the milk powder supplements using a randomised block design. Neither the investigators nor the subjects knew the number code that corresponded to the type of supplement. After laboratory analysis, group codes were disclosed for data analysis.

\section{Determination of dietary calcium intake and physical activity levels}

A questionnaire was administered before the study to collect information from the subjects and their parents on their health history, medication use, socio-economic status, pattern of dairy product consumption, and past and present intakes of $\mathrm{Ca}$ and vitamin D supplements. The daily dairy diary was used to record the frequency and quantity of consumption of the supplements. Information on the consumption of other dairy products and $\mathrm{Ca}$ or vitamin $\mathrm{D}$ supplements was also collected during interviews at the mid-trial and end-trial monitoring periods.

Dietary nutrient intake $(\mathrm{mg} / \mathrm{d})$ was assessed using $3 \mathrm{~d}$ (two weekdays and one weekend day) food records every 6 months; the FFQ was designed at Sun Yat-sen University 
and had forty-three items at 0 and 12 months. The validity of the FFQ was evaluated based on previous studies. Information regarding foods, including snacks, self-administered by the subjects was recorded in the $3 \mathrm{~d}$ food records. Details regarding food consumption were recorded by the subjects' guardians, who were instructed to estimate portions using household measures and food models, and validated via in-person interviews. The FFQ was administered by professionally trained researchers during face-to-face interviews. Chinese measures of standard-size bowls and spoons were used to quantify food items with the assistance of a set of food measuring models. These food diaries helped to monitor compliance to the intervention protocol and to assess longitudinal dietary intake throughout the study. Chinese food composition tables and a data entry program were used to calculate nutrient intake. The total daily dietary nutrient intake was calculated for each subject by averaging the results of these methods.

The number of hours that each student spent on daily physical activity was evaluated using a prospective $3 \mathrm{~d}$ (two weekdays and one weekend day) physical activity record adapted from Bouchard et al. ${ }^{(17,18)}$ at 0,6 and 12 months. Metabolic equivalents (MET) for each activity were calculated based on activity type, breath and heart rate. The $24 \mathrm{~h}$ energy expenditure for the physical activities was calculated based on the MET indicated in the questionnaire.

\section{Compliance}

Milk drinking diaries and $3 \mathrm{~d}$ food records were collected from the subjects to evaluate the interventional milk and daily food intakes and to verify whether the subjects consumed any other forms of milk or supplement. Milk intake during the intervention period was assessed from the number of remaining milk powder packages recorded in the milk drinking diary every month.

\section{Anthropometry and pubertal stage ascertainment}

The height, weight and blood pressure of each subject were measured at 0 and 12 months before DXA. The standing height was determined to the nearest $1 \mathrm{~mm}$ using a stadiometer. Weight was measured in light clothing without shoes to the nearest $0 \cdot 1 \mathrm{~kg}$. Blood pressure was measured to $1 \mathrm{mmHg}$ using a mercury sphygmomanometer.

Pubertal stage was ascertained by self-assessment using line drawings and written descriptions of the five stages of puberty, according to Tanner's definitions ${ }^{(19)}$. The pubertal status of girls was based on breast and pubic hair development and that of boys was based on genital and pubic hair development.

\section{Bone mineral assessment}

The BMC and BMD of the whole body, lumbar spine (L1-L4), left hip and femoral neck were measured by DXA scanning using a Lunar scanner (Lunar DPX-NT PRO; GE, Inc.) before and after the intervention. Bone mass accrual was calculated from these values. The subjects wore a cotton sport suit during scanning. The outcome scan was analysed with reference to the individual subject's baseline image using the DXA compare facility. The same technician performed all measurements. Quality assurance and long-term instrument stability were assessed by scanning the phantom at the beginning of each measurement day. Over the course of the 12 months of the study, the CV of BMD of the whole body, lumbar spine, left hip and femoral neck were 0.83, 0.64, 1.91 and $1.95 \%$, respectively, with no significant change over time.

\section{Statistical analyses}

Data were combined in EpiData 3.1 and Microsoft Excel 2007 databases, and statistical analyses were performed using the statistical software package SPSS for Windows 13.0 (SPSS, Inc.). Results are reported as means with their standard deviations. The baseline characteristics and bone mass of each group (combining girls and boys) were compared using a one-way ANOVA. An ANCOVA was performed to compare bone mass accrual among the groups for each sex after adjusting for confounding factors. The effect of $\mathrm{Ca}$ supplementation on BMC and BMD, independent of body size (height and weight), was calculated by the difference in measurements (1-year measurement - baseline measurement) and the percentage change (\%change/year). Other independent variables examined were age, pubertal status, Ca intake and physical activity. With the hierarchy of physical activity classifications or Tanner stages, a general linear model was used to determine the association between physical activity or sexual maturity and bone mass. By combining the girls and boys to enlarge the sample size in each group, $Z$-scores ((measurement - average)/SD) were used as independent variables to harmonise the sex difference and the covariates of age, weight, height, and dietary $\mathrm{Ca}, \mathrm{P}$, protein, and energy intakes were adjusted. Results were considered significant if $P<0.05$.

\section{Results}

A flowchart depicting participant selection process is shown in Fig. 1. Of the 220 subjects who were included in the study, 198 completed the 1-year intervention trial, with a dropout rate of $10 \%$. In total, twenty-two subjects withdrew from the study before completing the intervention trial. Of these twenty-two subjects, three dropped out to go abroad and nineteen withdrew as they did not want to continue taking the supplements. No side effects were reported due to supplement use during the intervention period. No significant differences were observed in the anthropometric or other measured characteristics between the subjects who withdrew from the study and those who completed the intervention trial (data not shown).

Complete datasets of the 198 subjects who completed the intervention trial were included in the final analysis. The overall compliance rate among those who completed the intervention trial was $92 \cdot 28 \%$, as determined by the maintenance of dietary intake records. The baseline characteristics of the intervention groups are given in Table 1 . There were no significant differences among the three groups with 


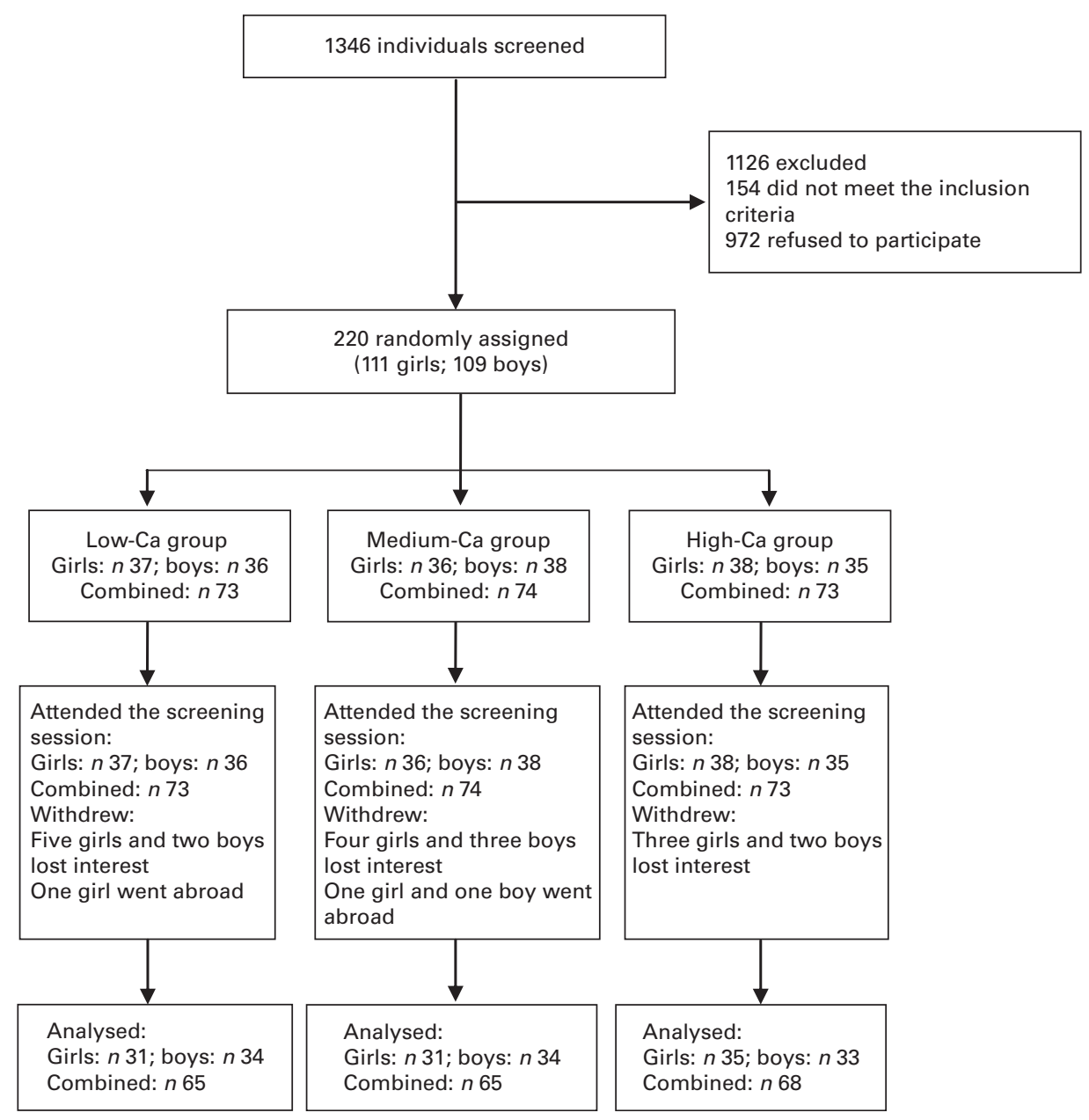

Fig. 1. Flowchart depicting participant selection process.

regard to anthropometric measurements, Tanner stage, nutrient intake, physical activity or bone mass at the measured sites for each sex.

Based on the FFQ used in the initial screening process, there were no significant differences in the baseline daily $\mathrm{Ca}$ intake levels in girls $(P=0.905)$ or boys $(P=0.407)$ among the low-Ca, medium-Ca and high-Ca groups. After the 1-year intervention, $\mathrm{Ca}$ intake levels in girls (including supplemental $\mathrm{Ca}$ ) in the low-Ca, medium-Ca and high-Ca groups were 706 (SD 148), 1011 (SD 238) and 1243 (SD 193) mg/d, respectively, and those in boys were 671 (SD 135), 985 (SD 168), and 1327 (sD 251) $\mathrm{mg} / \mathrm{d}$, respectively (Table 2). Because of the restriction imposed regarding consumption of other milk and dairy products during the present study, the interventional supplementation accounted for the incremental increases in $\mathrm{Ca}$ intake. Moreover, there was a decrease in $\mathrm{Ca}$ intake levels in all subjects due to dairy product restriction, and a very similar amount of $\mathrm{Ca}$ was added back to the diet via supplementation in the low-Ca group.

\section{Changes in bone mineral accretion}

No effect of $\mathrm{Ca}$ supplementation was observed on bone mass accretion after combining data from the boys and girls.
Furthermore, no significant differences were observed in BMC and BMD among the three intervention groups at 12 months. The bone mineral characteristics of the three intervention groups at the end of the 12-month intervention period are not reported.

All the measures increased over the 12-month intervention period in both girls and boys as would be expected during growth. However, the change was smaller in girls, including for height. Although there were no significant differences in the absolute changes in BMC or BMD in girls among all groups, the percentage change in BMC (\%BMC) of the femoral neck was significantly greater $(P=0.045$; ANOVA $)$. After controlling for covariates, girls in the high-Ca group had $3.3 \%$ greater BMC gains than those in the low-Ca group. However, there was no difference either between the high$\mathrm{Ca}$ and medium-Ca groups or between the medium-Ca and low-Ca groups (Table 3).

Absolute changes in the femur neck BMC of boys in the high$\mathrm{Ca}$ and medium-Ca groups were 0.555 (SD 0.130) and 0.579 (SD $0 \cdot 280) \mathrm{g}$, respectively, which were significantly greater than those of boys in the low-Ca group (0.429 (SD 0.150) g, $P<0.05)$. The \%BMC in the high-Ca and medium-Ca groups was greater than that in the low-Ca group (15.7 (SD 7.1) v. 11.7 (SD 7.6) \%, $P=0.03 ; 15.8($ SD $7 \cdot 8) v .11 \cdot 7$ (SD 7.6) \%, $P=0.03$, 
Table 1. Anthropometric, lifestyle and dietary characteristics of the study sample at baseline (Mean values and standard deviations)

\begin{tabular}{|c|c|c|c|c|c|c|c|c|c|c|c|c|c|c|}
\hline & \multicolumn{7}{|c|}{ Girls } & \multicolumn{7}{|c|}{ Boys } \\
\hline & \multicolumn{2}{|c|}{ Low $(n 31)$} & \multicolumn{2}{|c|}{ Medium ( $n$ 31) } & \multicolumn{2}{|c|}{ High ( $n$ 35) } & \multirow[b]{2}{*}{$P$} & \multicolumn{2}{|c|}{ Low (n 34) } & \multicolumn{2}{|c|}{ Medium ( $n$ 34) } & \multicolumn{2}{|c|}{ High ( $n$ 33) } & \multirow[b]{2}{*}{$P$} \\
\hline & Mean & SD & Mean & SD & Mean & SD & & Mean & SD & Mean & SD & Mean & SD & \\
\hline Age (years) & $12 \cdot 9$ & 0.4 & $12 \cdot 9$ & 0.3 & $12 \cdot 9$ & 0.3 & 0.671 & $12 \cdot 8$ & 0.5 & $12 \cdot 9$ & 0.4 & $13 \cdot 0$ & 0.4 & 0.259 \\
\hline Weight (kg) & $43 \cdot 8$ & $6 \cdot 0$ & $45 \cdot 2$ & 6.6 & $46 \cdot 0$ & $6 \cdot 0$ & 0.391 & $48 \cdot 0$ & 13.6 & 47.9 & 13.4 & $47 \cdot 8$ & 8.0 & 0.997 \\
\hline Height $(\mathrm{cm})$ & 154.2 & $5 \cdot 1$ & $155 \cdot 1$ & 4.4 & $156 \cdot 4$ & $5 \cdot 1$ & 0.179 & $157 \cdot 3$ & 8.7 & $156 \cdot 1$ & 9.7 & $156 \cdot 7$ & 7.9 & 0.853 \\
\hline $\mathrm{BMI}\left(\mathrm{kg} / \mathrm{cm}^{2}\right)$ & 18.5 & $2 \cdot 7$ & $18 \cdot 7$ & $2 \cdot 4$ & $18 \cdot 8$ & $2 \cdot 6$ & 0.969 & $19 \cdot 2$ & $4 \cdot 1$ & $19 \cdot 4$ & $4 \cdot 0$ & $19 \cdot 4$ & 2.6 & 0.492 \\
\hline BMI Z-scores* & 0.02 & 0.9 & 0.08 & 1.1 & 0.05 & 1.0 & 0.865 & 0.03 & 1.1 & 0.03 & $1 \cdot 1$ & 0.03 & 0.7 & 0.949 \\
\hline Tanner stage & \multirow{2}{*}{\multicolumn{4}{|c|}{3}} & \multirow{2}{*}{\multicolumn{2}{|c|}{5}} & 0.765 & & & & & & & 0.97 \\
\hline $1(n)$ & & & & & & & & \multicolumn{2}{|c|}{8} & \multicolumn{2}{|c|}{9} & \multicolumn{2}{|c|}{7} & \\
\hline $2(n)$ & \multicolumn{2}{|c|}{17} & \multicolumn{2}{|c|}{18} & \multicolumn{2}{|c|}{19} & & \multicolumn{2}{|c|}{21} & \multicolumn{2}{|c|}{21} & \multicolumn{2}{|c|}{22} & \\
\hline$\geq 3(n)$ & \multicolumn{2}{|c|}{10} & \multicolumn{2}{|c|}{10} & \multicolumn{2}{|c|}{11} & & \multicolumn{2}{|c|}{5} & \multicolumn{2}{|c|}{4} & \multicolumn{2}{|c|}{4} & \\
\hline Time since menarche (months) & $9 \cdot 1$ & $6 \cdot 2$ & $12 \cdot 7$ & 8.8 & $11 \cdot 0$ & 0.2 & 0.21 & - & & - & & - & & \\
\hline \multicolumn{15}{|l|}{ Dietary intake (per d) } \\
\hline Energy (kcal) & 1970 & 393 & 1968 & 392 & 1874 & 397 & 0.306 & 2222 & 531 & 2285 & 664 & 2555 & 693 & 0.081 \\
\hline Energy (kJ) & 8242 & 1644 & 8234 & 1640 & 7841 & 1661 & 0.306 & 9297 & 2222 & 9560 & 2778 & 10690 & 2900 & 0.081 \\
\hline Protein (g) & 77 & 24 & 78 & 20 & 70 & 22 & 0.159 & 88 & 34 & 89 & 34 & 98 & 33 & 0.371 \\
\hline $\mathrm{Ca}(\mathrm{mg}) \dagger$ & 706 & 276 & 685 & 209 & 710 & 221 & 0.905 & 690 & 239 & 720 & 226 & 765 & 220 & 0.407 \\
\hline$P(\mathrm{mg})$ & 1206 & 400 & 1147 & 299 & 1202 & 323 & 0.745 & 1212 & 34 & 1258 & 377 & 1390 & 356 & 0.141 \\
\hline PA $($ MET $\times \mathrm{h} / \mathrm{d}) \ddagger$ & $36 \cdot 1$ & 3.6 & 35.9 & $2 \cdot 6$ & 35.5 & $2 \cdot 4$ & 0.688 & $36 \cdot 5$ & 3.5 & $36 \cdot 4$ & $3 \cdot 1$ & $36 \cdot 6$ & 3.1 & 0.948 \\
\hline
\end{tabular}

PA, physical activity; MET, metabolic equivalents.

*No supplements were used; Z-score: (measurement- average)/SD.

$\dagger \mathrm{Ca}$ from the diet.

‡Evaluated by MET $(\mathrm{kJ} / \mathrm{kg} \times \mathrm{h})$. 
respectively). These differences remained significant after adjusting for covariates. There was no significant difference in BMC (absolute or percentage value) between the high-Ca and medium-Ca groups (Table 4).

\section{Physical activity and Tanner stage}

Based on the median value (34.86 MET) of 1-year physical activity levels, the subjects were divided into two groups. Neither the BMD $Z$-score change nor the BMC $Z$-score change was significantly different in subjects with physical activity levels $<34.86$ MET in the low-Ca, medium-Ca and high-Ca groups. However, subjects with physical activity levels $>34.86$ MET in the high-Ca and medium-Ca groups had greater whole-body BMD $Z$-score changes than those in the low-Ca group $(P=0.01$ and $P=0.02$, respectively). The spine (L1-L4) BMD $Z$-score changes were significantly greater in both the high-Ca and medium-Ca groups than in the low-Ca group ( $P=0 \cdot 04$; Table 5$)$.

The subjects were also stratified by median Tanner stage (Tanner stage $=3$ ). Significantly increased whole-body and femoral neck BMD $Z$-scores were observed in subjects with Tanner stage $<3$ in the high-Ca and medium-Ca groups. However, only the medium-Ca group had a higher left hip BMD $Z$-score than the low-Ca group. The medium-Ca and high-Ca groups had higher whole-body, femoral neck and femoral shaft BMC $Z$-scores than the low-Ca group (Table 6).

\section{Discussion}

This is the first randomised controlled trial that aimed to evaluate the effects of various doses of Ca supplementation in Chinese adolescents. The effects of Tanner stage and physical activity on bone response to different doses of Ca supplementation were also evaluated using a subgroup analysis. The 12-month intervention using 600 and $900 \mathrm{mg} / \mathrm{d} \mathrm{Ca}$, with actual total $\mathrm{Ca}$ intake levels being 1011 and $1243 \mathrm{mg} / \mathrm{d}$ for girls and 985 and $1328 \mathrm{mg} / \mathrm{d}$ for boys, led to significant increases in the \%BMC of the femoral neck. The increases were moderate, which is consistent with growth trends, although differences among the groups were not as large as expected. Furthermore, physical activity and Tanner stage were potential factors for bone mineral accretion. All groups were also supplemented with 200 IU vitamin D based on the Chinese DRI and assumed to have obtained adequate vitamin $\mathrm{D}$ amounts, allowing better control of the effect of vitamin D as a confounder on bone accretion. These findings reveal that $\mathrm{Ca}$ supplementation causes a clinically important decrease in the risk of osteoporosis and fractures and provides evidence for the need to formulate Ca DRI and dietary guidelines for Chinese adolescents.

The growth rate of limbs is greater than that of the spine before puberty and decelerates during the peripubertal years when axial growth accelerates ${ }^{(20)}$. In the present study, the magnitudes of the significant increase in bone accretion outcomes in the high-Ca group compared with those in the low-Ca group (the effect on \%BMC) at the femoral neck in girls and boys were 9.7 and $15.7 \%$, respectively. Thus, in adolescents of either sex, the overall developmental pattern of the femoral 
Table 3. Analysis of the means of bone measurements at baseline and after supplementation and the percentage change $\neq$ in these variables in girls

(Mean values and standard deviations)

\begin{tabular}{|c|c|c|c|c|c|c|c|c|}
\hline \multirow[b]{2}{*}{ Variables } & \multicolumn{2}{|c|}{ Low $(n 31)$} & \multicolumn{2}{|c|}{ Medium ( $n$ 31) } & \multicolumn{2}{|c|}{ High ( $n$ 35) } & \multirow[b]{2}{*}{ ANOVA } & \multirow[b]{2}{*}{ ANCOVA } \\
\hline & Mean & SD & Mean & SD & Mean & SD & & \\
\hline \multicolumn{9}{|c|}{ Bone mineral density $\left(\mathrm{g} / \mathrm{cm}^{2}\right)$} \\
\hline \multicolumn{9}{|l|}{ Whole body } \\
\hline Baseline & 0.995 & 0.071 & 1.007 & 0.093 & 1.000 & 0.082 & 0.857 & \\
\hline 1 year & 1.036 & 0.062 & 1.043 & 0.066 & 1.040 & 0.061 & 0.825 & \\
\hline Change & 0.038 & 0.019 & 0.036 & 0.021 & 0.035 & 0.022 & 0.988 & \\
\hline Percentage change & 3.6 & $2 \cdot 2$ & 3.8 & $2 \cdot 0$ & 3.6 & $2 \cdot 4$ & 0.884 & 0.606 \\
\hline \multicolumn{9}{|l|}{ Spine (L1-L4) } \\
\hline Baseline & 0.931 & $0 \cdot 121$ & 0.941 & 0.160 & 0.947 & 0.140 & 0.991 & \\
\hline 1 year & 0.999 & 0.112 & 1.0038 & 0.14 & 1.005 & 0.126 & 0.883 & \\
\hline Change & 0.061 & 0.032 & 0.059 & 0.037 & 0.053 & 0.036 & 0.926 & \\
\hline Percentage change & $6 \cdot 7$ & $5 \cdot 0$ & $6 \cdot 9$ & 4.0 & $6 \cdot 4$ & $5 \cdot 0$ & 0.758 & 0.487 \\
\hline \multicolumn{9}{|l|}{ Left hip } \\
\hline Baseline & 0.799 & 0.113 & 0.816 & 0.119 & 0.807 & 0.116 & 0.937 & \\
\hline 1 year & 0.838 & 0.109 & 0.850 & 0.127 & 0.847 & 0.104 & 0.767 & \\
\hline Change & 0.033 & 0.025 & 0.035 & 0.026 & 0.038 & 0.025 & 0.336 & \\
\hline Percentage change & $4 \cdot 1$ & 3.0 & $3 \cdot 9$ & $3 \cdot 2$ & 4.3 & 3.0 & 0.410 & 0.214 \\
\hline \multicolumn{9}{|l|}{ Femoral neck } \\
\hline Baseline & 0.866 & 0.103 & 0.871 & 0.127 & 0.876 & 0.111 & 0.965 & \\
\hline 1 year & 0.903 & $0 \cdot 101$ & 0.904 & 0.134 & 0.914 & 0.099 & 0.686 & \\
\hline Change & 0.037 & 0.028 & 0.038 & 0.033 & 0.044 & 0.036 & 0.219 & \\
\hline Percentage change & 4.5 & 3.5 & 4.5 & 3.8 & 5.4 & 4.4 & 0.533 & 0.286 \\
\hline \multicolumn{9}{|l|}{ Bone mineral content $(\mathrm{g})$} \\
\hline \multicolumn{9}{|l|}{ Whole body } \\
\hline Baseline & 1715 & 228 & 1776 & 306 & 1785 & 275 & 0.561 & \\
\hline 1 year & 1890 & 229 & 1959 & 279 & 1958 & 325 & 0.688 & \\
\hline Change & 171 & 75 & 183 & 85 & 179 & 74 & 0.386 & \\
\hline Percentage change & $10 \cdot 7$ & 5.3 & $10 \cdot 2$ & 4.5 & 10.5 & $5 \cdot 6$ & 0.363 & 0.161 \\
\hline \multicolumn{9}{|l|}{ Spine (L1-L4) } \\
\hline Baseline & $39 \cdot 1$ & 7.6 & 40.5 & $10 \cdot 0$ & $40 \cdot 1$ & $8 \cdot 1$ & 0.819 & \\
\hline 1 year & 44.0 & 7.6 & $45 \cdot 1$ & $7 \cdot 8$ & 44.9 & $8 \cdot 4$ & 0.724 & \\
\hline Change & $5 \cdot 2$ & $2 \cdot 6$ & 4.3 & $2 \cdot 6$ & 4.7 & 2.9 & 0.404 & \\
\hline Percentage change & $12 \cdot 6$ & 8.7 & $12 \cdot 1$ & 7.5 & $12 \cdot 8$ & $9 \cdot 1$ & 0.750 & 0.342 \\
\hline \multicolumn{9}{|l|}{ Left hip } \\
\hline Baseline & $22 \cdot 2$ & 3.2 & $22 \cdot 7$ & 4.0 & $22 \cdot 9$ & $3 \cdot 6$ & 0.692 & \\
\hline 1 year & 23.8 & 3.1 & $24 \cdot 1$ & $4 \cdot 3$ & $24 \cdot 2$ & $3 \cdot 3$ & 0.576 & \\
\hline Change & 1.5 & 0.9 & 1.4 & 0.8 & 1.4 & 0.9 & 0.832 & \\
\hline Percentage change & $6 \cdot 4$ & 4.9 & $7 \cdot 0$ & 4.5 & $6 \cdot 2$ & $5 \cdot 0$ & 0.881 & 0.484 \\
\hline \multicolumn{9}{|l|}{ Femoral neck } \\
\hline Baseline & 3.4 & 0.4 & 3.5 & 0.6 & 3.5 & 0.5 & 0.641 & \\
\hline 1 year & 3.6 & 0.5 & 3.7 & 0.6 & 4.0 & 0.5 & 0.318 & \\
\hline Change & 0.270 & 0.148 & 0.213 & 0.180 & 0.317 & 0.228 & 0.098 & \\
\hline Percentage change & 6.4 & 5.4 & $8 \cdot 2$ & 4.8 & $9 \cdot 7^{\star} \dagger$ & $5 \cdot 6$ & 0.045 & 0.022 \\
\hline
\end{tabular}

* Mean value was significantly different from that of the low-Ca group $(P<0.05$; ANOVA).

$\dagger$ Mean value was significantly different from that of the low-Ca group on adjusting for the following covariates: age change; weight change; height change; time since menarche; physical activity; dietary $\mathrm{Ca}, \mathrm{P}$, protein, and energy intakes $(P<0.05$; ANCOVA).

$\ddagger$ Percentage change: (values at follow-up - values at baseline) $\times 100 /$ (values at baseline).

neck observed in the present study did not differ very much from that reported previously ${ }^{(5,21)}$. The study conducted by Samantha et al. ${ }^{(21)}$ suggests that Ca supplementation significantly increases size-adjusted BMC of the femoral neck (2.2\%). Johnston et al. ${ }^{(22)}$ carried out a double-blind, placebo-controlled trial in twins showing a significant increase in BMD at two of the three femoral sites. However, the Cochrane Collaboration systematic review suggests that there are no effects of Ca supplementation on the femoral neck or lumbar spine BMD, but that there are small effects on the whole-body BMC and upper-limb $\mathrm{BMD}^{(23)}$. In a 12-month, double-blind, placebo-controlled trial with 1-year follow-up, 235 healthy prepubertal boys who ate Ca-enriched foods exhibited an increase in BMD at several appendicular skeleton sites (the radius, the hip and the femoral diaphysis), but not at the lumbar spine ${ }^{(24)}$. The differences in the appendicular sites observed after $\mathrm{Ca}$ supplementation in these studies may be a result of the different ethnicities, age groups, and levels of physical activity of the patients. There are substantial differences in bone mass growth according to age, sex and skeletal site. In females, at the levels of both the lumbar spine and femoral neck, most of the total gain in $\mathrm{BMD} / \mathrm{BMC}$ recorded between 9 and 18 years of age occurs within a 4-year period from 11 to 15 years of age. Later in life, BMD gain in females is dramatically reduced. In males, in whom bone mass accrual is delayed compared with that in females, the increase in bone mass at the levels of both the lumbar spine and femoral neck is particularly pronounced between 13 and 17 years of age ${ }^{(5)}$. 
Table 4. Analysis of the means of bone measurements at baseline and after supplementation and the percentage changeł in these variables in boys

(Mean values and standard deviations)

\begin{tabular}{|c|c|c|c|c|c|c|c|c|}
\hline \multirow[b]{2}{*}{ Variables } & \multicolumn{2}{|c|}{ Low (n 34) } & \multicolumn{2}{|c|}{ Medium ( $n$ 34) } & \multicolumn{2}{|c|}{ High (n 33) } & \multirow[b]{2}{*}{ ANOVA } & \multirow[b]{2}{*}{ ANCOVA } \\
\hline & Mean & SD & Mean & SD & Mean & SD & & \\
\hline \multicolumn{9}{|c|}{ Bone mineral density $\left(\mathrm{g} / \mathrm{cm}^{2}\right)$} \\
\hline \multicolumn{9}{|l|}{ Whole body } \\
\hline Baseline & 0.943 & 0.714 & 0.972 & 0.703 & 0.955 & 0.603 & 0.984 & \\
\hline 1 year & 0.986 & 0.602 & 1.023 & 0.706 & 1.010 & 0.610 & 0.959 & \\
\hline Change & 0.042 & 0.032 & 0.047 & 0.035 & 0.051 & 0.029 & 0.994 & \\
\hline Percentage change & $4 \cdot 3$ & 3.2 & $4 \cdot 8$ & 3.5 & $5 \cdot 3$ & 3.0 & 0.442 & 0.476 \\
\hline \multicolumn{9}{|l|}{ Spine (L1-L4) } \\
\hline Baseline & 0.782 & $0 \cdot 108$ & 0.819 & 0.125 & 0.798 & 0.108 & 0.916 & \\
\hline 1 year & 0.889 & 0.130 & 0.910 & 0.143 & 0.898 & 0.120 & 0.853 & \\
\hline Change & 0.094 & 0.032 & 0.090 & 0.047 & 0.088 & 0.041 & 0.997 & \\
\hline Percentage change & $12 \cdot 0$ & $3 \cdot 7$ & $11 \cdot 1$ & $6 \cdot 2$ & $11 \cdot 1$ & $5 \cdot 5$ & 0.867 & 0.915 \\
\hline \multicolumn{9}{|l|}{ Left hip } \\
\hline Baseline & 0.876 & 0.123 & 0.916 & 0.111 & 0.897 & 0.116 & 0.917 & \\
\hline 1 year & 0.938 & 0.165 & 0.980 & 0.120 & 0.967 & 0.124 & 0.776 & \\
\hline Change & 0.063 & 0.043 & 0.058 & 0.036 & 0.068 & 0.035 & 0.636 & \\
\hline Percentage change & $7 \cdot 1$ & $5 \cdot 0$ & $6 \cdot 4$ & 3.9 & $7 \cdot 8$ & 4.4 & 0.430 & 0.529 \\
\hline \multicolumn{9}{|l|}{ Femoral neck } \\
\hline Baseline & 0.853 & 0.115 & 0.890 & 0.126 & 0.882 & 0.123 & 0.936 & \\
\hline 1 year & 0.913 & 0.139 & 0.944 & 0.134 & 0.942 & 0.129 & 0.932 & \\
\hline Change & 0.065 & 0.076 & 0.051 & 0.039 & 0.058 & 0.044 & 0.986 & \\
\hline Percentage change & $7 \cdot 4$ & $4 \cdot 7$ & $5 \cdot 6$ & 4.2 & $7 \cdot 0$ & $5 \cdot 2$ & 0.260 & 0.368 \\
\hline \multicolumn{9}{|l|}{ Bone mineral content $(\mathrm{g})$} \\
\hline \multicolumn{9}{|l|}{ Whole body } \\
\hline Baseline & 1700 & 375 & 1754 & 377 & 1740 & 320 & 0.819 & \\
\hline 1 year & 2012 & 429 & 2059 & 411 & 2048 & 336 & 0.838 & \\
\hline Change & 311 & 108 & 295 & 100 & 319 & 105 & 0.490 & \\
\hline Percentage change & $18 \cdot 1$ & 4.8 & $17 \cdot 3$ & $6 \cdot 1$ & $18 \cdot 8$ & 6.5 & 0.569 & 0.651 \\
\hline \multicolumn{9}{|l|}{ Spine (L1-L4) } \\
\hline Baseline & 33.2 & 8.6 & 35.7 & $10 \cdot 0$ & 34.7 & 9.8 & 0.871 & \\
\hline 1 year & $42 \cdot 0$ & $10 \cdot 0$ & 43.9 & $12 \cdot 1$ & $44 \cdot 1$ & 10.5 & 0.571 & \\
\hline Change & $8 \cdot 6$ & $3 \cdot 3$ & 8.0 & $3 \cdot 2$ & 8.4 & $3 \cdot 3$ & 0.942 & \\
\hline Percentage change & $26 \cdot 2$ & 9.5 & 23.2 & 8.9 & $25 \cdot 2$ & 10.5 & 0.431 & 0.502 \\
\hline \multicolumn{9}{|l|}{ Left hip } \\
\hline Baseline & 23.7 & 5.4 & $24 \cdot 2$ & 5.5 & $24 \cdot 1$ & 5.5 & 0.912 & \\
\hline 1 year & $27 \cdot 8$ & $6 \cdot 0$ & $28 \cdot 1$ & $6 \cdot 8$ & 28.5 & $5 \cdot 6$ & 0.856 & \\
\hline Change & $4 \cdot 1$ & $1 \cdot 8$ & $3 \cdot 8$ & 1.6 & $4 \cdot 2$ & 1.6 & 0.485 & \\
\hline Percentage change & $18 \cdot 1$ & $8 \cdot 3$ & $16 \cdot 1$ & $7 \cdot 2$ & $18 \cdot 6$ & 8.5 & 0.397 & 0.448 \\
\hline \multicolumn{9}{|l|}{ Femoral neck } \\
\hline Baseline & $3 \cdot 7$ & 0.7 & $3 \cdot 8$ & 0.8 & $3 \cdot 7$ & 0.6 & 0.731 & \\
\hline 1 year & 4.2 & 1.0 & 4.3 & 0.9 & 4.3 & 0.7 & 0.862 & \\
\hline Change & 0.429 & 0.150 & $0.579^{*}$ & 0.280 & $0.555^{\star}$ & 0.130 & 0.005 & \\
\hline Percentage change & 11.7 & $7 \cdot 6$ & $15 \cdot 8^{*} \dagger$ & $7 \cdot 8$ & $15 \cdot 7^{\star} \dagger$ & $7 \cdot 1$ & 0.040 & 0.032 \\
\hline
\end{tabular}

* Mean value was significantly different from that of the low-Ca group $(P<0.05$; ANOVA).

† Mean value was significantly different from that of the low-Ca group on adjusting for the following covariates: age change; weight change; height change; physical activity; dietary $\mathrm{Ca}, \mathrm{P}$, protein, and energy intakes $(P<0.05$; ANCOVA).

$\ddagger$ Percentage change: (values at follow-up - values at baseline) $\times 100 /($ values at baseline).

Multiple studies that have evaluated the importance of adequate $\mathrm{Ca}$ intake for bone growth in preteen and adolescent children have been published ${ }^{(25)}$. Moreover, studies carried out by Jackman et al. ${ }^{(26)}$ and Matkovic \& Heaney ${ }^{(27)}$ have suggested that $\mathrm{Ca}$ retention in adolescents plateaus at a certain $\mathrm{Ca}$ intake level. If $\mathrm{Ca}$ intake is below this threshold, there is bone response. The total $\mathrm{Ca}$ intake levels in the low-Ca, medium-Ca and high-Ca groups in the present study were 706, 1011 and $1243 \mathrm{mg} / \mathrm{d}$ for girls and 671, 985 and $1328 \mathrm{mg} / \mathrm{d}$ for boys, respectively. The results of the assessment of changes in bone mineral accretion suggest that Ca requirements in 12- to 14-year-old girls might be higher than $1243 \mathrm{mg} / \mathrm{d}$ and that 12 - to 14 -year-old boys might require a minimum of $985 \mathrm{mg} \mathrm{Ca} / \mathrm{d}$. Weight loading on bones during childhood and adolescence is considered to be an important determinant of increased peak bone mass ${ }^{(12,28)}$. Some observational studies have suggested a positive association between physical activity and muscle strength, bone mass ${ }^{(9,12)}$ or bone growth $^{(29)}$. A number of intervention studies with weightbearing physical activity have confirmed a positive effect of physical activity on bone growth in children ${ }^{(30-32)}$. Tanner stage and physical activity levels were found to have different effects on the response of whole-body BMD and BMC to Ca supplementation in the present study. The effects of $\mathrm{Ca}$ supplementation in adolescents with high physical activity levels and low Tanner stage were more significant than 
Table 5. Association between calcium supplementation and bone mass change in adolescents ( $>34.86$ metabolic equivalents) after intervention†

(Mean values and standard deviations)

\begin{tabular}{|c|c|c|c|c|c|c|c|c|}
\hline \multirow[b]{2}{*}{$\mathrm{BMD}$ and $\mathrm{BMC}$} & \multicolumn{2}{|c|}{ Low $(n 30)$} & \multicolumn{2}{|c|}{ Medium ( $n$ 37) } & \multicolumn{2}{|c|}{ High ( $n$ 32) } & \multirow[b]{2}{*}{$P$} & \multirow[b]{2}{*}{$P_{\text {trend }}$} \\
\hline & Mean & SD & Mean & SD & Mean & SD & & \\
\hline \multicolumn{9}{|c|}{ BMC Z-score change } \\
\hline Whole body & 0.137 & 1.476 & $0.954^{*}$ & 1.840 & $0.921^{*}$ & 1.533 & 0.036 & 0.023 \\
\hline Spine (L1-L4) & 0.362 & 1.285 & $1.017^{\star}$ & 1.662 & $0.977^{*}$ & 1.545 & 0.045 & 0.031 \\
\hline Left hip & 0.167 & 1.755 & 0.587 & 1.704 & 0.797 & 1.479 & 0.217 & 0.083 \\
\hline Femoral neck & 0.091 & 1.726 & 0.604 & 1.793 & 0.761 & 1.500 & 0.266 & 0.063 \\
\hline \multicolumn{9}{|c|}{ BMC Z-score changeł } \\
\hline Whole body & 0.475 & 1.410 & 0.980 & 1.704 & 1.042 & 1.489 & 0.291 & 0.038 \\
\hline Spine (L1-L4) & 0.481 & 1.307 & 0.965 & 1.787 & 1.113 & 1.661 & 0.278 & 0.02 \\
\hline Left hip & 0.250 & 1.504 & 0.710 & 1.649 & 0.995 & 1.322 & 0.152 & 0.018 \\
\hline Femoral neck & 0.293 & 1.569 & 0.688 & 1.735 & 0.978 & 1.250 & 0.22 & 0.023 \\
\hline
\end{tabular}

BMD, bone mineral density; BMC, bone mineral content.

*Mean value was significantly different from that of the low-Ca group $(P<0.05)$.

† A general linear model was used with the following adjusted covariates: age; weight; height; Tanner stage; dietary Ca, $\mathrm{P}$, protein, and energy intakes.

$\ddagger Z$-score: (measurement - average)/sD (adjusted for intervention time).

those in adolescents with low physical activity levels and high Tanner stage. This finding is in contrast to the results of the Cochrane Collaboration systematic review, which indicated that pubertal stage, ethnicity, Ca intake or physical activity did not affect bone mineral accretion at any bone site $^{(26)}$. This discrepancy may be due to the wide range of subjects' age (3-18 years), baseline dietary intake levels (280-1200 mg) and supplemental Ca doses (300-1200 mg) in the Cochrane review ${ }^{(26)}$. Ca supplements have different effects depending on subjects' age and habitual $\mathrm{Ca}$ intake levels. Several studies have suggested that $\mathrm{Ca}$ requirements are high during the first two decades of life ${ }^{(33-35)}$, and Ca supplements are more beneficial to children, such as prepubertal children ${ }^{(22)}$ and Chinese children with habitually low $\mathrm{Ca}$ intake levels, i.e. $400-500 \mathrm{mg} / \mathrm{d}$ from the time of weaning ${ }^{(36-38)}$. The present study subjects had Ca intake levels of $402 \cdot 8-467 \cdot 4 \mathrm{mg} / \mathrm{d}$, which may explain the inconsistent results.
The present study has several limitations. First, the intervention period was not long enough to effectively demonstrate the effect of $\mathrm{Ca}$ supplementation on bone mineral accretion. Second, the Ca supplementation doses selected were not sufficiently high to identify a threshold for girls. Finally, limited by laboratory equipment, BMC and BMD were measured by DXA rather than by peripheral quantitative computed tomography (pQCT). Although DXA is widely used, it is less precise than PQCT.

The present study and other published controlled trials support the hypothesis that an increase in $\mathrm{Ca}$ intake levels in adolescents enhances bone accretion. However, the magnitudes of bone accretion as a result of Ca supplementation in these short-duration trials were moderate and comparable. The results of the present study and other short-duration $\mathrm{Ca}$ trials indicate that $\mathrm{Ca}$ supplements of $300-900 \mathrm{mg} / \mathrm{d}$ in addition to $\mathrm{Ca}$ amounts received during daily dietary intake

Table 6. Association between calcium supplementation and bone mass change in adolescents (Tanner stage $<3$ ) after intervention $\ddagger$

(Mean values and standard deviations)

\begin{tabular}{|c|c|c|c|c|c|c|c|c|}
\hline \multirow[b]{2}{*}{$\mathrm{BMD}$ and $\mathrm{BMC}$} & \multicolumn{2}{|c|}{ Low (n 28) } & \multicolumn{2}{|c|}{ Medium ( $n$ 25) } & \multicolumn{2}{|c|}{ High ( $n$ 34) } & \multirow[b]{2}{*}{$P$} & \multirow[b]{2}{*}{$P_{\text {trend }}$} \\
\hline & Mean & SD & Mean & SD & Mean & SD & & \\
\hline \multicolumn{9}{|c|}{ BMD Z-score change§ } \\
\hline Whole body & -0.074 & 1.487 & $0.751^{*} \dagger$ & 1.592 & $0.745^{\star}$ & 1.435 & 0.014 & 0.034 \\
\hline Spine (L1-L4) & 0.132 & $1 \cdot 202$ & $0 \cdot 715^{\star}$ & 1.113 & $0 \cdot 655^{\star}$ & 1.451 & 0.046 & 0.162 \\
\hline Left hip & -0.140 & 1.550 & $0.741^{*}$ & 1.620 & 0.443 & 1.201 & 0.019 & 0.116 \\
\hline Femoral neck & -0.186 & 1.432 & $0.492^{*}$ & 1.348 & $0.431^{*}$ & $1 \cdot 126$ & 0.011 & 0.051 \\
\hline \multicolumn{9}{|c|}{ BMC $Z$ score change§ } \\
\hline Whole body & 0.218 & 1.368 & $0.636^{*} \dagger$ & 1.364 & $0.924^{*}$ & 1.346 & 0.038 & 0.033 \\
\hline Spine (L1-L4) & 0.312 & $1 \cdot 242$ & 0.542 & $1 \cdot 125$ & 0.765 & 1.496 & 0.253 & 0.188 \\
\hline Left hip & 0.060 & 1.354 & $0.624^{*}$ & 1.519 & $0.709^{*}$ & 1.097 & 0.047 & 0.057 \\
\hline Femoral neck & 0.026 & 1.512 & $0.450^{*}$ & 1.457 & $0 \cdot 763^{*}$ & 1.086 & 0.040 & 0.028 \\
\hline
\end{tabular}

BMD, bone mineral density; BMC, bone mineral content

${ }^{*}$ Mean value was significantly different from that of the low-Ca group $(P<0.05)$.

$\dagger$ Mean value was significantly different from that of the high-Ca group $(P<0.05)$.

$\ddagger$ A general linear model was used with the following adjusted covariates: age; weight; height; physical activity; dietary Ca, $P$, protein and energy intakes.

$\S Z$-score: (measurement - average)/SD (adjusted for intervention time). 
result in a narrow intake range among the supplemental intervention groups. This range does not seem to have a great impact in terms of additional bone mineral accretion of the whole body and does not result in a plateau, especially in girls. Due to the limited number of subjects of each sex in the present study, the data had to be combined to determine the effect of $\mathrm{Ca}$ supplementation, which resulted in the study appearing underpowered. To determine appropriate Ca intake levels for Chinese adolescents, long-duration intervention trials, a greater number of subjects, a suitable range of supplement doses and specific bone accretion indices are required. Furthermore, examination of the efficiency of $\mathrm{Ca}$ absorption is another key issue in estimating Ca requirements in adolescents.

In addition, serum 25-hydroxyvitamin D and qualitative sun exposure assessments would be useful when analysing results in future studies. Adequate dietary intake of Ca and vitamin D in children is important to guarantee normal bone mineralisation and to prevent rickets. The onset of puberty stimulates the metabolism of 25-hydroxyvitamin D to calcitriol and subsequently increases $\mathrm{Ca}$ absorption in the intestine, decreases urinary $\mathrm{Ca}$ excretion and promotes Ca deposition in bones ${ }^{(39)}$.

\section{Conclusion}

The results of the present study indicate that an increase in $\mathrm{Ca}$ intake contributes to bone mass accrual in adolescents, although the effect is moderate. However, the increase in femoral neck mineral content is likely to result in a clinically important decrease in the risk of osteoporosis and fractures, as it is a recommended site for the diagnosis of osteoporosis with DXA and where fractures are common besides the lumbar spine. The results also suggest that adolescents should increase their physical activity levels to augment the effects of Ca supplementation on bone mass accretion and that $\mathrm{Ca}$ supplementation is more effective in early puberty than in late puberty.

\section{Acknowledgements}

The authors thank all the adolescents, parents and teachers who participated in the study.

The present study was supported by research grants from the Eleven Five-Year project of the Chinese National Ministry of Science and Technology (2008BAI58B02).

The authors' contributions are as follows: X.-m. M. recruited and investigated the subjects, performed the statistical analyses and drafted the manuscript; Y.-X. S. designed the study and helped draft the manuscript; Z.-W. H., X.-g. Y. and Y.-X. S. conceived and designed the study. All authors read and approved the final manuscript.

None of the authors has any conflicts of interest to declare.

\section{References}

1. Food and Nutrition Board, Institute of Medicine (2011) Dietary Reference Intakes for Vitamin D and Calcium. Washington, DC: National Academy Press.
2. Rizzoli R, Bianchi ML, Garabedian M, et al. (2010) Maximizing bone mineral mass gain during growth for the prevention of fractures in the adolescents and the elderly. Bone 46, 294-305.

3. Public Health Service, Office of Surgeon General (2004) Bone Health and Osteoporosis: A Report of the Surgeon General. Rockville, MD: Office of Surgeon General.

4. Du X, Zhu K, Trube A, et al. (2004) School-milk intervention trial enhances growth and bone mineral accretion in Chinese girls aged 10-12 years in Beijing. Br J Nutr 92, 159-168.

5. Bonjour JP, Theintz G, Buchs B, et al. (1991) Critical years and stages of puberty for spinal and femoral bone mass accumulation during adolescence. J Clin Endocrinol Metab 73, 555-563.

6. Anderson JJ (2000) The important role of physical activity in skeletal development: how exercise may counter low calcium intake. Am J Clin Nutr 71, 1384-1386.

7. Davies JH, Evans BAJ \& Gregory JW (2005) Bone mass acquisition in healthy children. Arch Dis Child 90, 373-378.

8. Lotborn M, Bratteby LE, Samuelson G, et al. (1999) Wholebody bone mineral measurements in 15-year-old Swedish adolescents. Osteoporos Int 9, 106-114.

9. Kristinsson JO, Valdimarsson O, Steingrimsdottir L, et al. (1994) Relation between calcium intake, grip strength and bone mineral density in the forearms of girls aged 13 and 15. J Intern Med 236, 385-390.

10. Boot AM, de Ridder MA, Pols HA, et al. (1997) Bone mineral density in children and adolescents: relation to puberty, calcium intake, and physical activity. J Clin Endocrinol Metab 82, 57-62.

11. Kardinaal AF, Ando S, Charles P, et al. (1999) Dietary calcium and bone density in adolescent girls and young women in Europe. J Bone Miner Res 14, 583-592.

12. Welten DC, Kemper HC, Post GB, et al. (1994) Weightbearing activity during youth is a more important factor for peak bone mass than calcium intake. J Bone Miner Res $\mathbf{9}$, 1089-1096.

13. Lee WT, Leung SS, Leung DM, et al. (1996) A follow-up study on the effects of calcium-supplement withdrawal and puberty on bone acquisition of children. Am J Clin Nutr 64 71-77.

14. Matkovic V, Goel PK, Badenhop-Stevens NE, et al. (2005) Calcium supplementation and bone mineral density in females from childhood to young adulthood: a randomized controlled trial. Am J Clin Nutr 81, 175-188.

15. Chinese Nutrition Society (2006) Chinese DRIs. Beijing: China Light Industry Press.

16. Lee WT, Leung SS, Ng MY, et al. (1993) Bone mineral content of two populations of Chinese children with different calcium intakes. Bone Miner 23, 195-206.

17. Bouchard C, Tremblay A, Leblanc C, et al. (1983) A method to assess energy expenditure in children and adults. $A m \mathrm{~J}$ Clin Nutr 7, 461-467.

18. Bouchard C (1997) Bouchard three day physical activity record. Med Sci Sports Exerc 29, s19-s24.

19. Tanner JM (1962) Growth at Adolescence, 2nd ed. Oxford, UK: Blackwell Scientific.

20. Iuliano-Burns S, Stone J, Hopper JL, et al. (2005) Diet and exercise during growth have site-specific skeletal effects: a co-twin control study. Osteoporos Int 16, 1225-1232.

21. Samantha JS, Ann P, Sarah CJ, et al. (2003) Effect of a calcium and exercise intervention on the bone mineral status of 16-18-y-old adolescent girls. Am J Clin Nutr 77, 985-992.

22. Johnston CC Jr, Miller JZ, Slemenda CW, et al. (1992) Calcium supplementation and increases in bone mineral density in children. $N$ Engl J Med 327, 82-87. 
23. Winzenberg TM, Shaw K, Fryer J, et al. (2006) Calcium supplementation for improving bone mineral density in children. The Cochrane Database of Systematic Reviews 2006, issue 2, CD005119.

24. Chevalley T, Bonjour JP, Ferrari S, et al. (2005) Skeletal site selectivity in the effects of calcium supplementation on areal bone mineral density gain: a randomized, doubleblind, placebo-controlled trial in prepubertal boys. J Clin Endocrinol Metab 90, 3342-3349.

25. Lanou AJ, Berkow SE \& Barnard ND (2005) Calcium, dairy products, and bone health in children and young adults: a reevaluation of the evidence. Pediatrics $\mathbf{1 1 5}$, 736-743.

26. Jackman LA, Millane SS, Martin BR, et al. (1997) Calcium retention in relation to calcium intake and postmenarcheal age in adolescent females. Am J Clin Nutr 66, 327-333.

27. Matkovic V \& Heaney RP (1992) Calcium balance during human growth: evidence for threshold behavior. Am J Clin Nutr 55, 992-996.

28. Ulrich CM, Georgiou CC, Gillis DE, et al. (1999) Lifetime physical activity is associated with bone mineral density in premenopausal women. J Womens Health $\mathbf{8}$, 3365-3375.

29. Slemenda CW, Reister TK, Hui SL, et al. (1994) Influences on skeletal mineralization in children and adolescents: evidence for varying effects of sexual maturation and physical activity. J Pediatr 125, 201-207.

30. Macdonald HM, Kontulainen SA, Khan KM, et al. (2007) Is a school-based physical activity intervention effective for increasing tibia bone strength in boys and girls? J Bone Miner Res 22, 434-446.
31. Welch JM, Turner CH, Devareddy L, et al. (2008) High impact exercise is more beneficial than dietary calcium for building bone strength in the growing rat skeleton. Bone $\mathbf{4 2}$, 660-668.

32. Yung PS, Lai YM, Tung PY, et al. (2005) Effects of weight bearing and non-weight bearing exercises on bone properties using calcaneal quantitative ultrasound. Br J Sports Med 39, 547-551.

33. Leitch I \& Aitken FC (1959) The estimation of calcium requirement: a reexamination. Nutr Abstr Rev 29, 393-411.

34. Garn SM (1970) The Earlier Gain and Later Loss of Cortical Bone in Nutritional Perspective. Springfield, IL: Charles C. Thomas.

35. American Academy of Pediatrics, Committee on Nutrition (1978) Calcium requirements in infancy and childhood. Pediatrics 62, 826-834.

36. Wang S, Xu YC, Li D, et al. (1996) Effect of calcium supplementation on bone mineral content in children accustomed to low calcium diet. Acta Nutri Sinica 18, 97-102.

37. Lee WT, Leung SS, Leung DM, et al. (1997) Bone mineral acquisition in low calcium intake children following the withdrawal of calcium supplement. Acta Paediatr 86, 570-576.

38. Dibba B, Prentice A, Ceesay M, et al. (2000) Effect of calcium supplementation on bone mineral accretion in Gambian children accustomed to a low-calcium diet. Am J Clin Nutr 71, 544-549.

39. Wastney ME, Ng J, Smith $\mathrm{D}$, et al. (1996) Differences in calcium kinetics between adolescent girls and young women. Am J Physiol 271, R208-R216. 